\title{
Research and Application of Ice Model of High Voltage Transmission Lines
}

\author{
Guo Lisa ${ }^{a}$, Guo Wei, Peng Zhiwei ${ }^{b}$, E Dejun, Cong Zhongxiao, Zhou Wei \\ College of Electrical Engineering, GuiZhou University, Guiyang 550003, China \\ aemail: 373196924@qq.com, b65821033@qq.com
}

Keywords: High-voltage Lines; Ice; Line Weight Load; Horizontal Stress

\begin{abstract}
This article mainly analyzed the existing transmission lines ice mechanics calculation model of the amount of ice, the key to calculate transmission lines ice, the amount of calculation is proposed considering the tower to wire length, horizontal stress and vertical than three critical loads of linear stress analysis calculation model ice. Using MALAB software programming for simulation, Validated the original mathematical model, and solved the difficult problem of model validation. Studied the theory of ice and extract the main factors influencing the ice, broadened the thinking Angle, from the perspective of practical application of ice monitoring calculation model and forecast calculation model $\mathrm{l}$ is established. Using actual data of Guizhou province power grid transmission lines ice compared with the simulation results of mathematical model of this paper, verify the transmission lines ice monitoring model were accuracy, practicability and feasibility.
\end{abstract}

\section{Introduction}

To satisfy the economic development of China, the increasing power load, and also constantly improved the voltage level of transmission lines, the management on transmission line become more and more difficult. Transmission line's environment is very complex, low temperature, freezing rain, wet snow, and freezing weather can cause serious transmission lines ice. World ice disaster accidents often happened [2].

In order to strengthen the transmission line, especially the operation monitoring of the high voltage transmission, and timely grasp the change of the transmission line running environment ,which needs to construct transmission line on-line monitoring system, so it could monitor operation conditions and master line running environment in time, provide technical support to eliminate a hazard .Early transmission lines ice monitoring mainly rely on artificial patrol ,which affected by terrain environment, weather conditions and other factors is bigger, and the low efficiency and long cycle .With the development of science and technology. Transmission line on-line monitoring system for the development work advanced rapidly in recent year. China are also carried out extensive research, has made many fruitful results.

From the current transmission line on-line monitoring system, both at home and abroad, in engineering application, which based on video image processing technology can make qualitative judgment of transmission conductor ice situation, and based on the transmission line equation of state of early warning technology can provide a quantitative analysis of monitoring data, the main method is weighing method, horizontal tension Angle, Angle-sag, wire stress measurement method[3,7], including weighing method and video image method to get more applications, achieved good practical effect.

\section{The Mathematical Model of Tower Stress}

\section{Overhead line load}

Usually a tension of transmission line has two tensions and a number of straight line towers, as shown Figure 1. Tension tower always design to be relatively strong, which can absorb a certain amount of imbalance tension, instead of straight line tower may be the whole tension weak link, this paper studies the stress of the straight of line tower. Overhead line state equation can be used to 
analyze wire change from one state to another state changes between each parameter, so that you can establish the link between the three calculation, thus solving the equivalent of the weight of the ice and ice thickness[8].

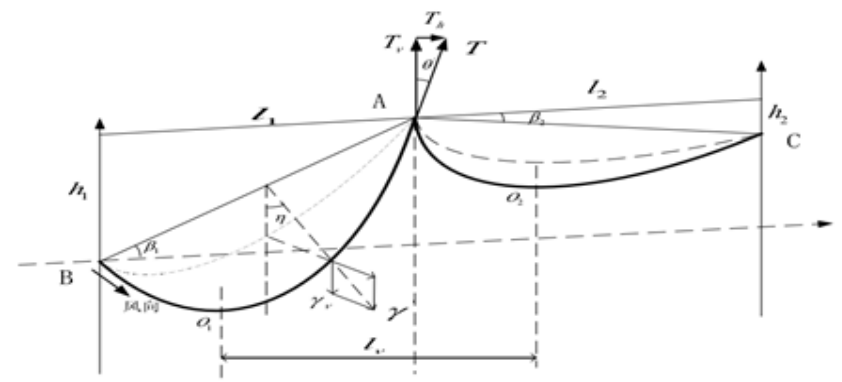

Figure 1 Model of the overhead lines with straight tower

About mechanical model, the load of gravity, ice and wind should be considered. Wind load could by two-dimensional Angle sensor to measure the wind Angle of the wire, monsoon was flat and do mechanics analysis on the plane.

1) Line weight load

Overhead line by the condition of no ice, the line load caused by wire itself quality, calculation formula is:

$$
\gamma_{0}=\frac{g q}{\mathrm{~s}}
$$

For the line weight load, $\mathrm{N} / \mathrm{m}^{*} \mathrm{~mm}^{2}$; g is the acceleration of gravity, $\mathrm{m} / \mathrm{s}^{2}$; q is quality of wires per unit length, $\mathrm{kg} / \mathrm{m}$; $\mathrm{S}$ is wire cross-sectional area, $\mathrm{mm}^{2}$;

2) Line weight load with ice

Overhead line when there is ice on the road, caused by the ice load

$\gamma_{\text {ice }}=\frac{\mathrm{g} \rho(d+b) \cdot 1 e 3}{\mathrm{~s}}$

$\mathrm{d}$ is diameter of wire, $\mathrm{mm}$; $\mathrm{b}$ is the thickness of the ice, $\mathrm{mm}$; $\rho$ is The density of ice, $\mathrm{kg} / \mathrm{m}^{3}$;

3) Vertical load

Overhead line under the condition of ice, wire vertical load is the combination of quality and quality of ice wire itself .

$\gamma_{v}=\gamma_{\text {ice }}+\gamma_{0}$

\section{Dynamic Tension and Angle Measurement Device}

A. Tension sensor

This paper adopt borui company BH-12 tension sensor. Voltage output and the pulling force conversion formula is pull $=1016+5.8 \mathrm{x}$ voltage, voltage unit is $\mathrm{mV}$, pull the unit is $\mathrm{kg}$.

B. Angle sensor

This article used the borui company production of 120T-30 dual-axis tilt sensors, output voltage and Angle conversion formula is: Angle = (output voltage-2.5)/Angle sensitivity .

\section{State equation of Overhead line}

For wire between two poles or few tower, with large elevation difference of overhead line equation of state could derive the ice coating of overhead lines, wire ice conditions of horizontal stress can be obtained, and the specific calculation formula is:

$$
\sigma_{\text {ice }}^{3}+\left(-\sigma_{0}+\frac{l^{2} \gamma_{0}^{2} E}{24 \sigma_{0}^{2}} \cos ^{2} \beta+\alpha E\left(t_{\text {ice }}-t_{0}\right) \cos \beta\right) \sigma_{\text {ice }}^{2}-\frac{l^{2} \gamma_{v}^{2} E}{24} \cos ^{2} \beta=0
$$

a is wire temperature linear expansion coefficient, $\mathrm{E}$ is elastic coefficient of wires. 


\section{Calculation of line ice}

According to the actual pull and angle of the line sensors we measured, we could calculated the parameters, and take these parameters into to line parallel load equation, so equation of state could be calculated. According experience that, calculated the theoretical value and practical value, maybe there is errors, in order to solve this errors, this article adopts the method of iterative.

\section{Calculation of Simulation}

\section{Basic Data of Line}

Basic data of Guizhou grid for $220 \mathrm{kv}$ transmission line: the overhead conductor adopts LGJ400/35 steel core aluminum stranded wire, a diameter is $27.62 \mathrm{~mm}$, cross-sectional area is $598.8486 \mathrm{~mm}^{2}$, quality of unit length of $1.569 \mathrm{~kg} / \mathrm{m}$, wire design temperature is 15 temperature of the conductor linear expansion coefficient of $2.10 \mathrm{x} 10-5 /{ }^{\circ} \mathrm{C}$, the elastic coefficient of conductor is $66 \mathrm{kN} / \mathrm{mm}^{2}$.\#15, \#16 and \#17 straight line tower group as an example for analysis, \#16 straight line tower the conductor is hanging with the suspension insulator string and the total weight is $283.2 \mathrm{~kg}$. \#15 side suspension point of $36.72 \mathrm{~m}$, \#17 large lateral suspension level $63 \mathrm{~m}$, \#15 side conductor span 381m, \#17 side conductor span 405m. Through the field measurement of the actual data are shown in table 1 below. By computing the ice thickness calculation in this paper, the mechanical model ice quality and equivalent thickness in table2, the actual data and calculated data as shown in figure2.

Table1 Field data

\begin{tabular}{|c|c|c|c|c|c|}
\hline $\begin{array}{c}\text { Date } \\
\text { Time }\end{array}$ & $\begin{array}{c}\text { Wind } \\
(\mathrm{m} / \mathrm{s})\end{array}$ & $\begin{array}{c}\text { temperature } \\
(\mathrm{C})\end{array}$ & $\begin{array}{c}\text { pull } \\
(\mathrm{N})\end{array}$ & $\begin{array}{c}\text { Angle } \\
(\text { degree })\end{array}$ & $\begin{array}{c}\text { Thickness( } \\
\mathrm{mm})\end{array}$ \\
\hline 2013.12 .27 & 5 & -3 & 10378.42 & 3.16 & 3.64 \\
\hline 2014.01 .05 & 4 & -5 & 10480.75 & 4.21 & 6.67 \\
\hline 2014.01 .20 & 7 & -6 & 12026.62 & 3.78 & 8.63 \\
\hline 2014.01 .21 & 2 & -3 & 10124.18 & 2.56 & 2.98 \\
\hline 2014.01 .25 & 8 & -4 & 10366.54 & 3.66 & 4.39 \\
\hline 2014.01 .26 & 6 & -3 & 10252.69 & 3.42 & 4.12 \\
\hline 2014.01 .28 & 5 & -5 & 10156.74 & 3.98 & 4.38 \\
\hline
\end{tabular}

\section{Simulation Calculation Data}

This article use large elevation difference load formula and overhead line equation of state, according to the parameters of the sensor, and through the horizontal stress and vertical relationship load, calculated equivalent thickness and quality .

Table2 Calculation data

\begin{tabular}{|c|c|c|c|c|c|c|c|}
\hline $\begin{array}{c}\text { Date } \\
\text { Time }\end{array}$ & $\begin{array}{c}\text { Wind } \\
(\mathrm{m} / \mathrm{s})\end{array}$ & $\begin{array}{c}\text { temperature } \\
(\mathrm{C})\end{array}$ & $\begin{array}{c}\text { Pull } \\
(\mathrm{N})\end{array}$ & $\begin{array}{c}\text { Angle } \\
(\text { degree })\end{array}$ & $\begin{array}{c}\text { Quality(Kg/ } \\
\mathrm{Km})\end{array}$ & $\begin{array}{c}\text { Thicknes } \\
\mathrm{s}(\mathrm{mm})\end{array}$ & $\begin{array}{c}\text { Errors( } \\
\%)\end{array}$ \\
\hline 2013.12 .27 & 5 & -3 & 10378.42 & 3.16 & 7.101 & 3.52 & 3 \\
\hline 2014.01 .05 & 4 & -5 & 10480.75 & 4.21 & 13.214 & 6.50 & 2.62 \\
\hline 2014.01 .20 & 7 & -6 & 12026.62 & 3.78 & 16.604 & 8.95 & 3.58 \\
\hline 2014.01 .21 & 2 & -3 & 10124.18 & 2.56 & 4.116 & 2.69 & 10.78 \\
\hline 2014.01 .25 & 8 & -4 & 10366.54 & 3.66 & 8.037 & 4.29 & 2.33 \\
\hline 2014.01 .26 & 6 & -3 & 10252.69 & 3.42 & 7.692 & 3.80 & 8.42 \\
\hline 2014.01 .28 & 5 & -5 & 10156.74 & 3.98 & 8.251 & 4.35 & 0.69 \\
\hline
\end{tabular}

Comparing line actual data with application model date in this paper, the results of comparison results were shown in figure 2, below. It can be seen that the errors are very small; And also showed that the model of calculation tallies with the field data. Verification shows that the ice monitoring model of the transmission line monitoring ice situation has accuracy, practicability and feasibility. 


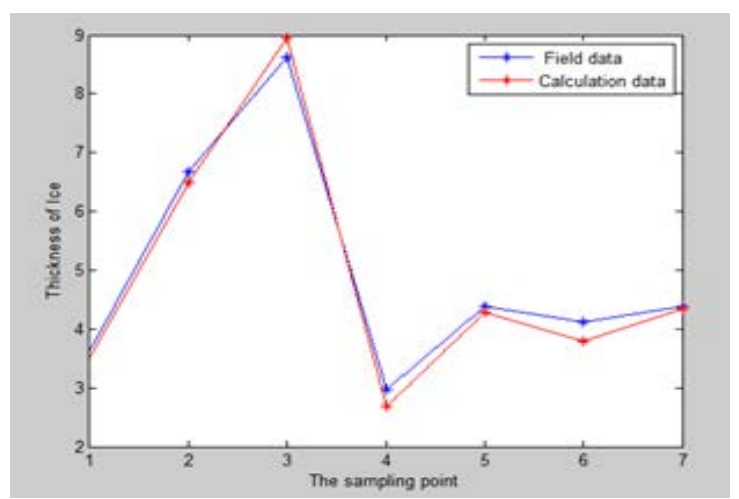

Figure2. Comparison of models

\section{Conclusion}

In this article, through analysis of overhead transmission lines in guizhou province, and mechanics calculation model of the amount of ice force, through the parameters obtained the sensor, combining with the circuit state equation and the formula to calculate transmission lines ice load .

Further study the structure of transmission line and tower and tower and transmission lines between the mechanical force, put forward using transmission line equation of state and vertical load calculation method. Comprehensive interpretation of the relationship between transmission lines ice load and gravity load, is presented based on the transmission line equation of state and vertical ice monitoring model of transmission lines. By comparing the field data and the theoretical calculation results, it shows that the ice monitoring model of the transmission line monitoring ice situation has accuracy, practicability and feasibility.

\section{Statement}

This article was fund by Study of the Mathematical Model Ice Online Monitoring Technology of High Voltage Transmission Lines, which supported by graduate innovation fund of guizhou university, item number is 2014041.

\section{References}

[1]Hu Guorong. Transmission lines basic theory[M]. BeiJing:China electric power press,2009.

[2]Lu Jiazheng, Zhang Xianhong, Fang Zheng. Ice disaster monitoring results and its analysis Hunan power system [J].Power system protection and control,2009,37(12):99.105.

[3]Fu Bing, Li Zhongtian. the real-time monitoring system of Ice and wind load on the transmission line[J]. China power,2001,34(4):47-48.

[4]M.Farzaneh, J.L.Laforte. Ice Accretion on Conductors Energized by AC or DC-A Laboratory Investigation of Ice Treeing[J].International Journal of Offshore an Polar Engineering, 1994, 4(1): 40.

[5]P.Personne and J.F.Gayet.Ice Accretion on Wires and Anti-Icing induced by joule effect [J].Journal of Applied meteorology,1987, 27(15):101-104.

[6]Yuan LiYu, Jiang Xingliang, Yi Hui. Transmission lines ice research status at home and abroad [J].High voltage technology,2003,30(1):6-9.

[7]Lenhard RW. An indirect method for estimating the weight of glaze on wires[J]. Bull. Amen. Meteor Soc, 1955(36):1-5.

[8]Makkonen L. Modeling power line icing in freezing precipitation[C].7th international workshop on atmospheric icing of structures,1996,Canada,195-200. 